\title{
Development of a Training System for Lathe Operation Using a Simulator with Relationship between Speed of Tool Feed and Cutting Sound/Shape of Chips
}

\author{
Takashi Kawashimo \\ Casio Computer Co., Ltd, Japan \\ Daisuke Doyo \\ Faculty of Business Administration, Kanagawa University, Japan \\ Tatsuya Yamaguchi, Ryosuke Nakajima, Toshiyuki Matsumoto* \\ Department of Industrial and Systems Engineering, Aoyama Gakuin University, Japan
}

(Received: September 1, 2014 / Revised: February 16, 2015; May 20, 2015 / Accepted: May 20, 2015)

\begin{abstract}
The recent manufacturing industry in Japan has found it difficult to transfer skills from trained workers to inexperienced workers because the former ages and then retires. This is a particular problem for lathe process, as this operation requires explicit and tacit knowledge, and defining the skills clearly in a manual is difficult. This study aims to develop a training system for lathe operation by using a simulator; this includes formulas that help define the relationship between the speed of tool feed and cutting sound/shape of chips which were proposed in the preceding study. The developed training system is verified the effectiveness.
\end{abstract}

Keywords: Lathe Operation, Training, Simulator, Speed of Tool Feed, Cutting Sound, Cutting Shape

* Corresponding Author, E-mail: matsumoto@ise.aoyama.ac.jp

\section{INTRODUCTION}

Recently the manpower, time, and money that the manufacturing industry in Japan can afford are decreasing because the youth are moving away from this industry. Many trained and skilled workers had retired around 2007 in Japan and it caused their skills disappear. We call it the 2007 problem in Japan. In addition, trained skilled workers are advancing in age and retiring; transferring their skills accumulated over the years is difficult. The Ministry of Economy, Trade and Industry (2007) says that $49.4 \%$ of new workers require $2 \sim 3$ years of training, and $28.1 \%$ require $4 \sim 5$ years. In the manufacturing industry, it can take years before a worker becomes sufficiently skilled at his/her work, and even more years are needed by trained workers to acquire advanced skills. In small and medium-sized manufacturing industries, there is no established system for the transfer of skills, so cost and time have become large problems. The personnel expenses to train a new worker alongside a trained worker are said to double to maintain the production volume and sales at the same level as the previous year (Shimizu et al., 1997). Owing to the lack of technical personnel responsible for the technology infrastructure in terms of 
both quantity and quality, an education and training method to effectively improve the skill level of a worker in a short period of time is required in production. Skill for production can be divided into explicit knowledge and tacit knowledge.

This study considers the lathe operation, which was also targeted in the preceding study; this process involves cutting stainless steel into shapes and is performed frequently. There are many studies for training the lathe operation with virtual reality or a simulator (Antonietti et al., 2001; Liang et al., 2011). But these do not treat the relationship between the speed of tool feed and cutting sound/shape of chips.

The preceding study has proposed a method and formulas describing the relationship between the speed of tool feed and cutting sound/shape of chips for the lathe operation based on an experiment with a trained worker with 52 years' experience (Kawashimo et al., 2012). The study focuses on one type of precision machining lathe work and investigates relationship between the speed of tool feed and the cutting sound/shape of chips, with aim of developing a simulator-based training system for use in preparatory training prior to OJT. As a result, the following findings were obtained; Cutting sound does not show monotonically increasing or decreasing, because this is affected by many factors in the range of small or large speed of feed. Diameter and spacing of chips become smaller with the increase of speed of feed. Moreover the relationships were formalized as shown with formulas (1)-(4).

This study aims to develop a training system for lathe operation with a simulator using the formulas proposed in the preceding study, to conduct an experiment with the developed system, and to verify the effectiveness of the system.

\section{DEVISING OF A TRAINING METHOD}

The devised training method consists of the following content: explicit and tacit knowledge. Explicit knowledge is transferred by training evaluation, and tacit knowledge is transferred by simulator training (Fukushima 2009; Nakajima et al., 2008; Takechi, 2005).

A method for extracting skill for production and designing a training system using "objects-changes analysis" is proposed (Nakamura, 2003; Doyo et al., 2009; Takeshima et al., 2014). Application of the method to lathe operation expresses the structure in Figure 1 and finds the relationship between the product, process and result. The product is a work piece before and after, the process includes handling and sound, and the result shows chips as remains.

\subsection{Transfer of Explicit Knowledge}

Three aspects of explicit knowledge are described here: handling, sound, and chips.

\subsubsection{Transfer of Handling as Explicit Knowledge}

Handling is transferred as explicit knowledge based on the average feed rate, stability of feed rate, difference in feed rate, and feed time series average of a trained worker and through a cumulative graph of feed amount in Figure 2 as an example. The average feed rate is obtained from the simulated feed results (Kawashimo et al., 2012). The stability of the feed rate is evaluated according to the standard deviation of five levels: a score of 5 is the best. The differences in the feed rate and feed time series average of a trained worker imply the difference between the absolute value of the time series feed and the goal value of $0.05 \mathrm{~mm} / \mathrm{rev}$ feed. These are evaluated

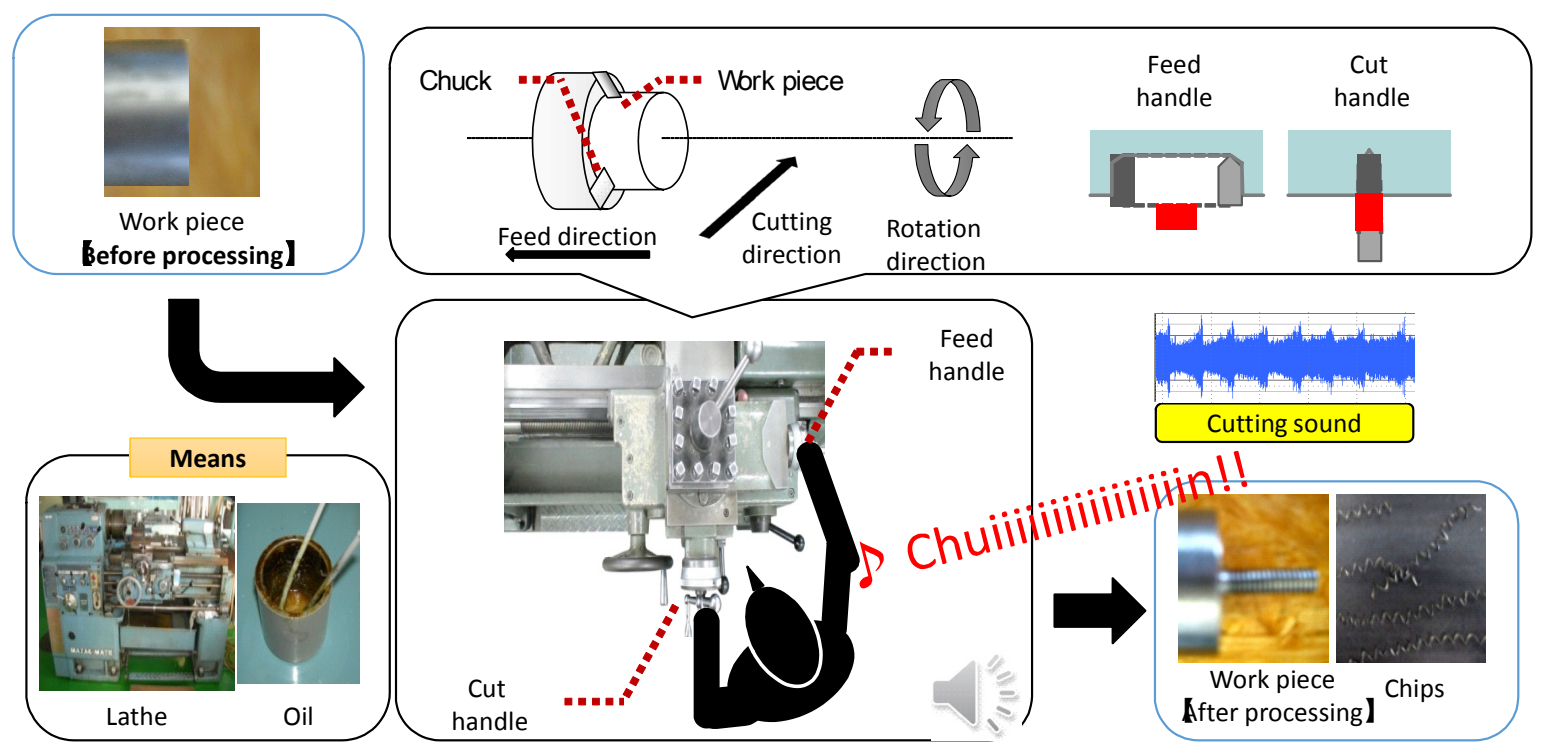

Figure 1. Structure of lathe operation. 
on three stages: best, good, and bad. They are also calculated according to the ratio of the previous three items. The total score is calculated on a scale of 100 points using (a) the amount of average feed rate and (b) the stability of the feed rate as base values and (c) the difference in feeding time series feed rate and average of a trained worker as an additional value. In this case the score goes to the point 61.6 which are a $16, \mathrm{~b} 32$ and c 13.6. The average feed rate is evaluated on five levels: fast, slightly faster, just right, somewhat slow, and slow in the comments column. The stability is similarly evaluated on five levels: very good, good, a little more, bad, and very bad.

The cumulative graph of feed amount is displayed by pressing a button on the right-hand side of the screen in Figure 3; it compares the results for a trainee and trained worker. The trainee can obtain feedback on handling from these items.

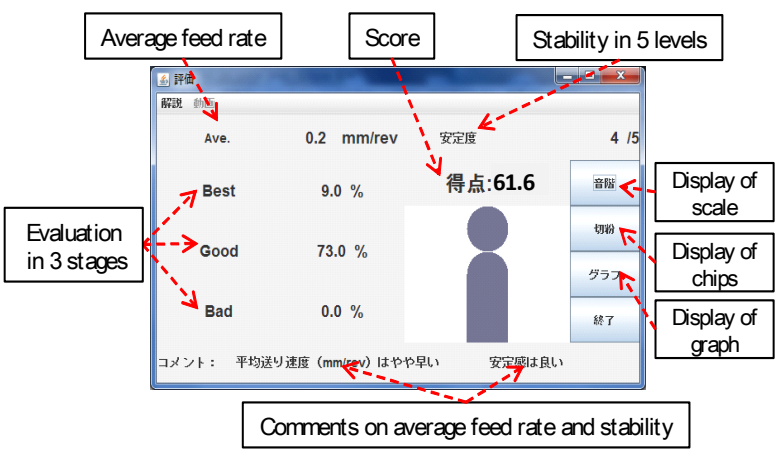

Figure 2. Evaluation screen for handling.

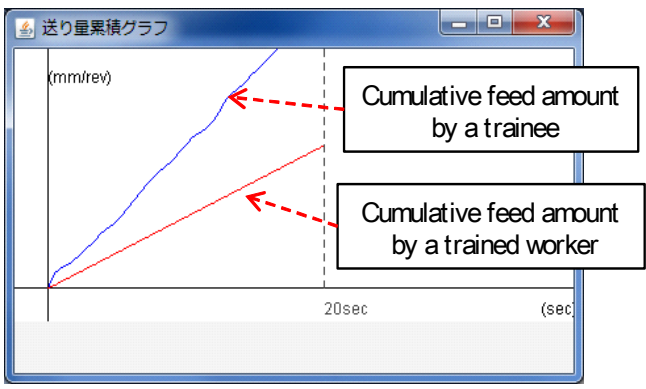

Figure 3. Cumulative graph of feed amount.

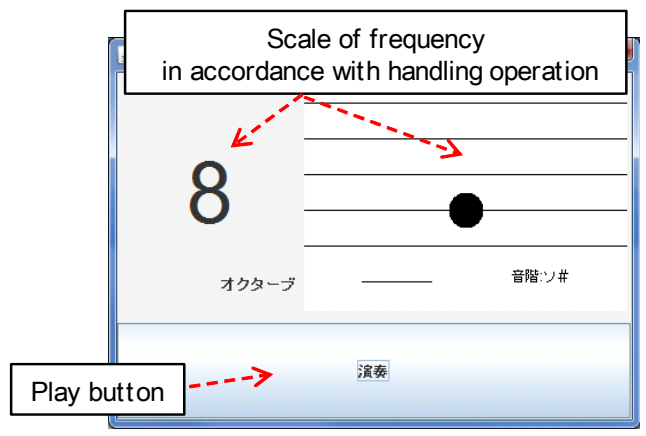

Figure 4. Evaluation screen for sound.

\subsubsection{Transfer of Sound as Explicit Knowledge}

Sound is transferred as explicit knowledge through a display of the musical scale for the sound frequency in Figure 4 (Suzuki et al., 2006). The sound frequency varies depending on the amount of cutting feed; this is converted to a musical scale and displayed. The sound is expressed on the musical scale rather than as a frequency to facilitate better and easier visualization. For example, people can more easily understand the expression " $\mathrm{F} \# 7$ octave" rather than "sound of a 3,000 Hz frequency." A trainee can receive feedback from the musical scale according to the amount of handle feed and difference with the target (Nakamura, 1999). The goal value is $F \# 7$ octave. This item is the original point of this study.

The sound frequency $(\mathrm{Hz})$ will be calculated along with the amount of cutting feed ( $\mathrm{mm} / \mathrm{rev}$ ) by the following formulas (1) and (2) proposed in the preceding study (Kawashimo et al., 2012).

$$
\begin{array}{cc}
S_{l}=\frac{100}{F_{a}}+1,500 & \left(F_{a}<=0.065\right) \\
S_{h}=\frac{F_{a}^{2}}{8} \times 1.9 \times 10^{6}+2,000 & \left(F_{a}>0.065\right)
\end{array}
$$

Where $F_{a}(\mathrm{~mm} / \mathrm{rev})$ is the amount of cutting feed, $S_{l}(\mathrm{~Hz})$ is the sound frequency in the lower $F_{a}$ part, and $S_{h}(\mathrm{~Hz})$ is the same in the higher $F_{a}$ part.

\subsubsection{Transfer of Chips as Explicit Knowledge}

Chips are transferred as explicit knowledge based on the diameter and interval of the simulated helix for 3D chip configuration and the thickness and width for the volume of one spiral chip in Figure 5. The 3D simulator shows chips corresponding to the average feed amount being handled. The trainee receives feedback by comparing this figure. The goal values are diameter; 8.3 $\mathrm{mm}$ and interval; $8.94 \mathrm{~mm}$.

The shape of chip, diameter and interval ( $\mathrm{mm})$, will be calculated along with the amount of cutting feed (mm/rev) by the following formulas (3) and (4) proposed in the preceding study (Kawashimo et al., 2012).

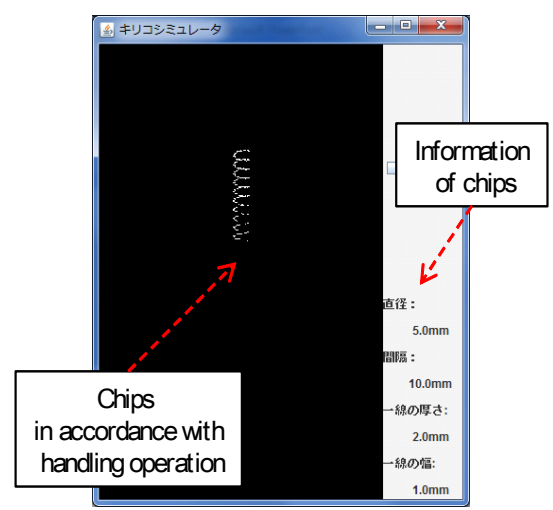

Figure 5. Evaluation screen for chips. 


$$
\begin{aligned}
& D_{s}=-9.07 F_{a}+9.40 \\
& I_{s}=-10.95 F_{a}+10.31
\end{aligned}
$$

Where $D_{s}(\mathrm{~mm})$ is the diameter of spiral and $I_{s}$ $(\mathrm{mm})$ is the interval of spiral in chip.

\subsection{Transfer of Tacit Knowledge}

Three aspects of tacit knowledge are described here: handling, sound, and chips. The transfer of tacit knowledge requires direct communication of the represented sense instead of a numerical representation as for explicit knowledge.

\subsubsection{Transfer of Handling as Tacit Knowledge}

Handling is transferred as tacit knowledge by manipulating handle of the simulator in Figure 8 below. The feed amount of handling is acquired by moving a mouse attached to the lathe bench according to the blade movement in the horizontal direction by handle rotation with $1 \mathrm{~mm}$ measurement accuracy. The trainee can understand the feed amount of handling by looking at the screen. The black bar in Figure 8(3) extends from right to left according to the rotation amount of the handling and represents the workpiece cutting status. Also the red bar shows the feed amount by a trained worker. The trainee can perform training exercises by comparing his/her feed the trained worker's feed and level up in rank by adjusting the display after becoming accustomed to a given exercise. The sound frequency of cutting decreases when oil is injected; in the simulation, this is done by left-clicking another mouse. The trainee can acquire the proper feed amount while actually operating the handle using tacit knowledge.

\subsubsection{Transfer of Sound as Tacit Knowledge}

Sound is transferred as tacit knowledge by listening to the simulated sound of cutting without mechanical noise. Sound travels from PC speakers (or the equivalent) according to the feed amount of being handled. The trainee judges the quality of the feed by listening to the sound of the pseudo-cutting calculated with formulas (1) and (2) without mechanical noise.

\subsubsection{Transfer of Chips as Tacit Knowledge}

Chips are transferred as tacit knowledge by looking at the shape. When transferring chips as explicit knowledge, the chip shape is represented by a numerical value. However, actually measuring the diameter and spacing of the chips in actual practice is not desirable because this takes time and effort. Ideally, the quality should be judged at a glance. The trainee obtains the chip form as tacit knowledge by visualizing the chip shape according to the feed amount on the display screen.

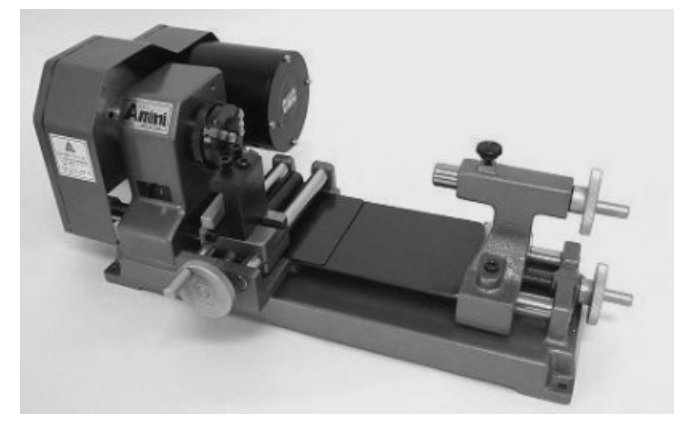

Figure 6. Tabletop lathe.

\section{DEVELOPED TRAINING SYSTEM}

The training system consists of the tabletop lathe shown in Figure 6 (Amini: No.1,100). This tabletop lathe can be used with a household power supply and can create workpieces up to $60 \mathrm{~mm}$ in diameter. This lathe also has processing functions such as cutting an outer diameter and boring holes as well as a large conventional lathe. It has sufficient functions for training on lathe operations.

Figure 7 and 8 shows the developed training system with this lathe. A mouse is used with this lathe to obtain data on the feed amount of being handled and to simulate lathe operation. The sound of pseudo-cutting can be heard during the simulation, and explicit knowledge on the handling, sound, and chips can be obtained after the simulation. This allows trainees to obtain feedback from the simulated results and learn on their own. The training system is effective and no unnecessary material costs are incurred. On the other hand, possible disadvantages include the time and effort needed for development. Therefore, the training system should have a realistic simulation and additional functions not found in practice. In this study, we developed a training system using the free software Eclipse 3.2 and Java.

\section{DESIGN OF EXPERIMENT}

Using the training system described in the previous section, the training system was experimentally verified as to whether it effectively improved a trainee's skills by transferring tacit and explicit knowledge on topics such as handling, sound, and chips. Eight university students with no experience were selected as subjects and classified into three groups based on the preliminary grouping experiment. Two groups of subjects practiced lathe operations with the training system, and the other group practiced without it. The results were then used to compare the degrees of improvement in skills of the three groups. 


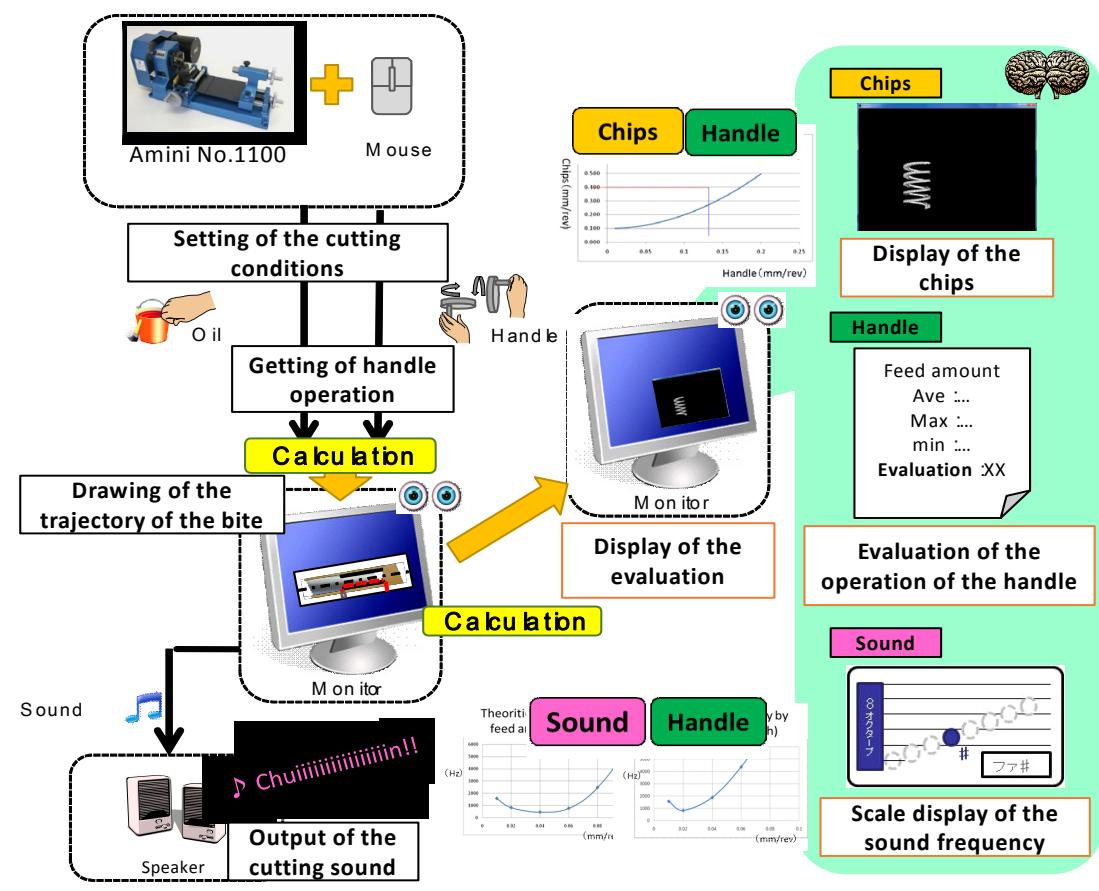

Figure 7. Overall picture of the training system.

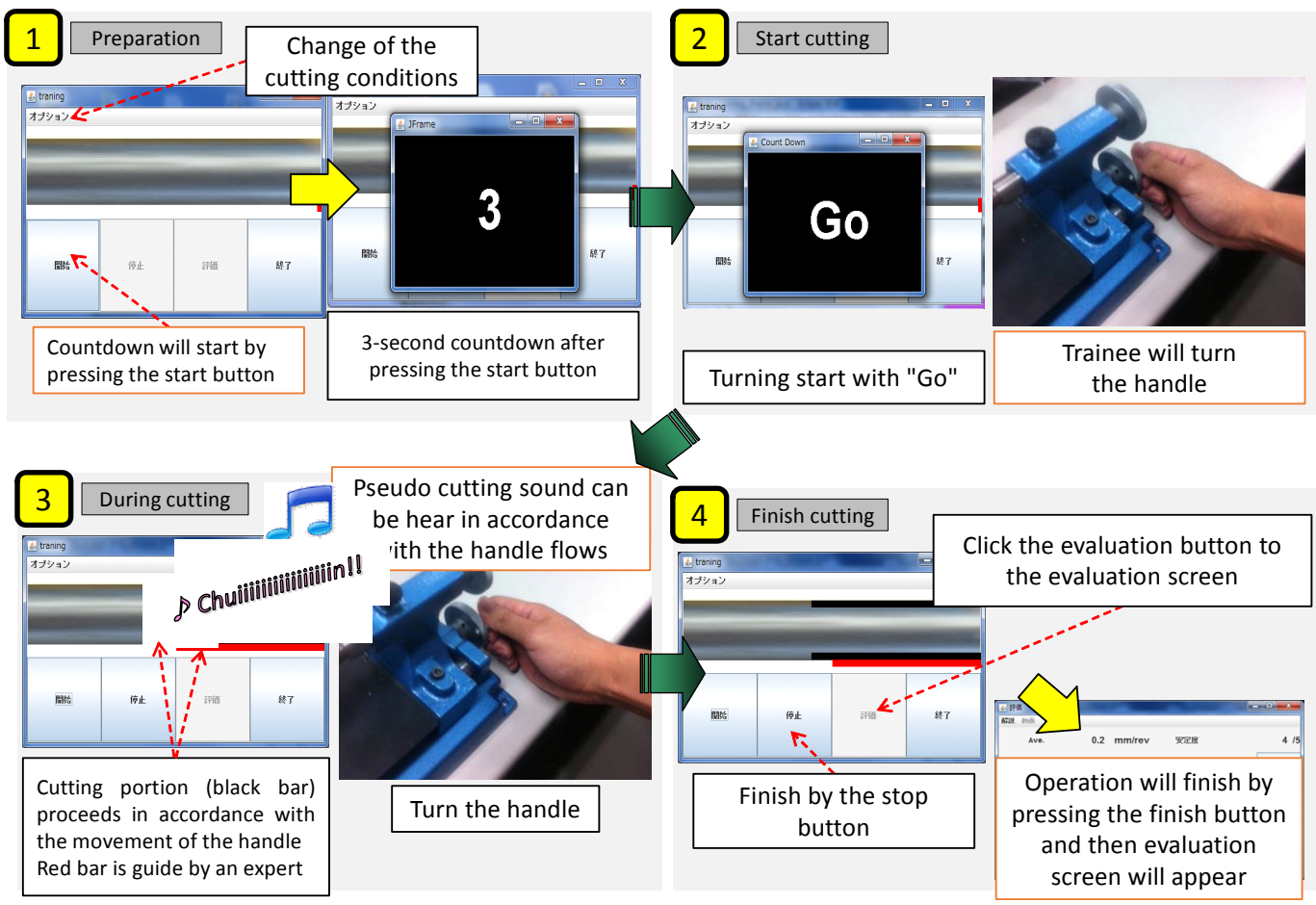

Figure 8. Procedure of the training system.

\subsection{Grouping Experiment}

The Eight subjects were classified into three groups based on dexterity so that no differences caused by a subject's individual ability would appear in the subsequent experiment which is original one in the study. For the grouping experiment, subjects were asked to make a minicar run on the scoreboard $(0,10,30,50,80,100,0)$ in Figure 9 using their hand and guess the number where it would stop in three trials. This experiment measures the subjects' dexterity, coordination, and nerves. These basic abilities are required for lathe operation. 


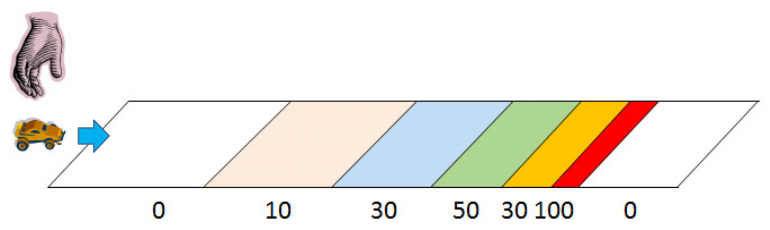

Figure 9. Task for grouping experiment.

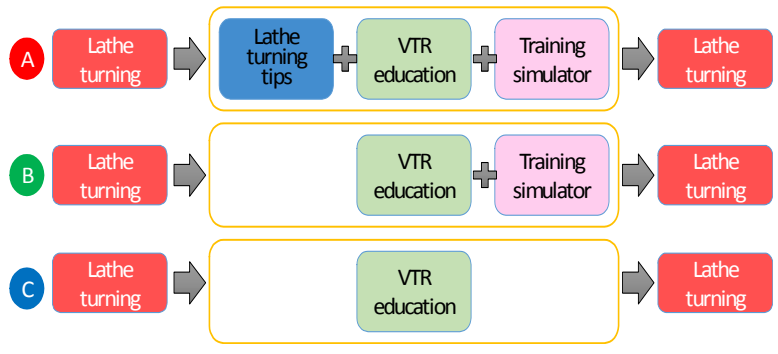

Figure 10. Training experiment.

\subsection{Verification of Training Experiment}

In this experiment in Figure 10, the effectiveness of the developed training system was verified. Two of the three groups (i.e., groups $\mathrm{A}$ and $\mathrm{B}$ ) used the training systems, and group $\mathrm{C}$ did not. Group A conducted training using the training system and receiving tips for lathe operation and VTR of feeding behavior from a trained worker. The tips simply summarized the cutting chip sound and how to achieve this or change it with a constant feed rate, how to maintain low resistance during cutting, and how to clean the surface of the workpiece. Group B conducted training using the training system and VTR of the feeding behavior from a trained worker. Group C only saw VTR of the feeding behavior from a trained worker. Viewing VTR is equivalent to the traditional teaching method of apprenticeship; the superiority of the developed system can be verified through this experiment. Subjects performed lathe operations three times; this involved cutting outlines in stainless steel. They received training during each operation. The termination condition for the training system was more than 85 points for the first time, more than 90 points for the second time, and being successful three times in a row. The upper time limit was $10 \mathrm{~min}$. The training effect for lathe operation was verified based on four criteria: resulting feed amount of the handle, cutting sound frequency, chip thickness, and workpiece surface.

\section{EXPERIMENTAL RESULTS AND DISCUSSION}

\subsection{Grouping Experiment}

The eight subjects were put into three groups. Figure 11 shows the total points after the grouping experiment was conducted three times. The subjects were classified

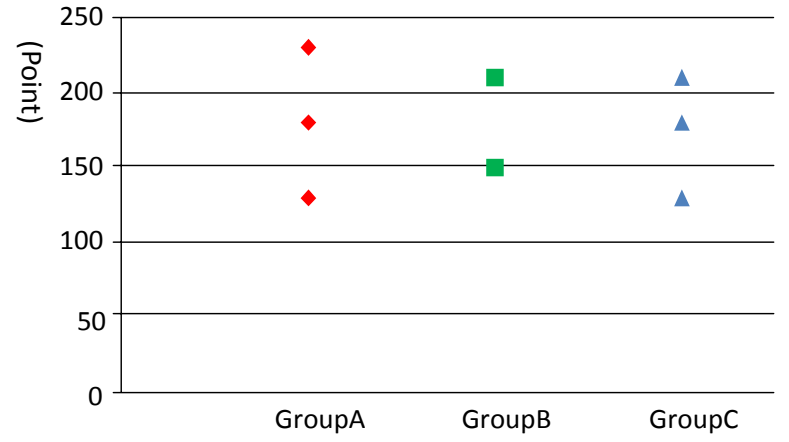

Figure 11. Result of grouping experiment.

so that the groups would have similar average results. Group A had three subjects with an average of 180.0 points, Group B had two subjects with an average of 180.0 points, and Group $\mathrm{C}$ had three subjects with an average of 173.3 points.

\subsection{Training Experiment}

The verification of training experiment was conducted as described above for the three groups. Figure 12 shows the training experiment. The upper-left graph in Figure 12 shows a box-whisker plot with the changes in the feed amount of being handled by group A for three lathe operation trials. The data were measured every second as sampling, then each trial has from 20 to 80 values depends on the length of time. The graph shows the average feed amount of handled by the subjects in the group and the average, maximum and minimum values. The middle and lower-left graphs in Figure 12 show the results for groups B and C, respectively. Group A has reached a proper and stable speed for the feed amount being handled after repeated trials. The results for group B are almost the same average and standard deviation of feed amount of handling in the third trial as those of group A. On the other hand, group $\mathrm{C}$ uses a faster speed for the feed amount of being handled than the other groups, and the speed is unstable throughout the trials.

The center graphs in Figure 12 show the changes in the cutting sound frequency. The graphs show the average frequency of the subjects in each group and the average, maximum and minimum values. For groups $\mathrm{A}$ and $\mathrm{B}$, the lower limit of the frequency decreases in the second trial and increases in the third trial. Confusion over the modified feed amount during training and blank time in the feed amount might have led to the above result in the second trial. For groups $\mathrm{A}$ and $\mathrm{B}$, their skills have improved based on the slight decrease in the upper limit of the frequency. For group C, the average frequency decreases, and the upper limit of the frequency is higher than that for the other groups.

The right graphs in Figure 12 show the changes in the chip thickness. The chip shape is determined by the feed amount of being handled; the chip shape thickness 


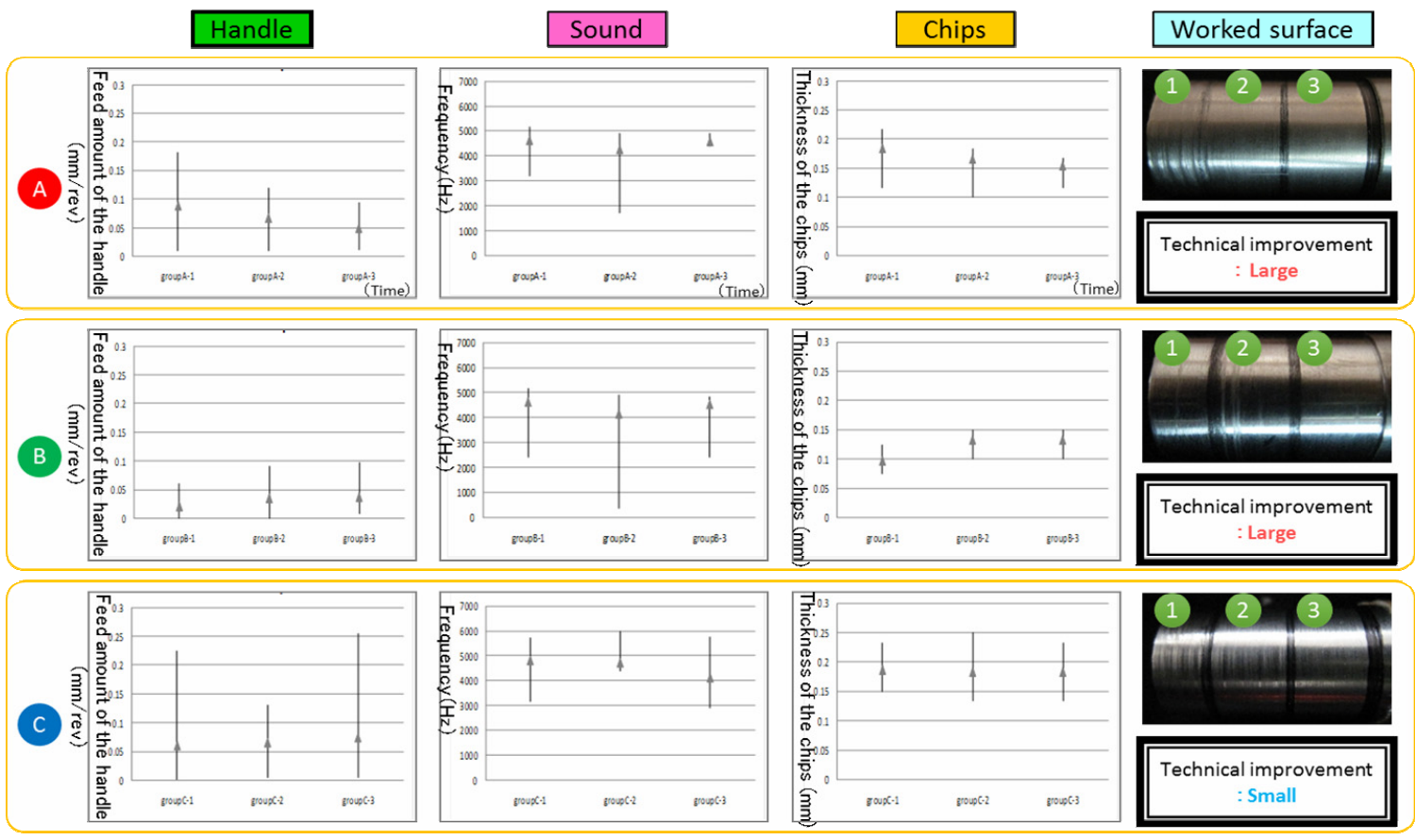

Figure 12. Result of training experiment.

is determined independently by the entry spiral and spacing of the front line for the circle width. Only the chip thickness is discussed here. The graphs show the average chip thickness and the average, maximum and minimum values of each group. For group A, the average chip thickness decreases. For group $\mathrm{B}$, the value increases. For groups $\mathrm{A}$ and $\mathrm{B}$, the maximum and minimum widths in the third trial are smaller than in the first trial. This means that the training system has improved the trainees' skills with regard to chip thickness. For group $\mathrm{C}$, the average chip thickness is stable, but the value is larger than that of the other two groups, and the maximum and minimum widths show no tendencies. These graphs are very similar to the transition of the feed amount being handled as shown in the left graphs in Figure 12. Thus, groups A and B show improved skill with regard to chip thickness, similar to the improvement in skill for feed amount being handled.

The same results are shown on the workpiece surface after machining (i.e., processed surface). The upper-right photo in Figure 12 shows the surface processed by a subject in group $\mathrm{A}$. The processed surface in the first trial has chatter owing to linear cracks, but the surfaces in the second and third trials are cleaner and have less chatter. The results for group B, which are shown in the middle-right photo in Figure 12, are almost the same as those for group A. For group C, whose results are shown in the lower-right photo in Figure 12, although the chatter of the processed surface in the third trial is thin, the roughness of the surface shows no change. Thus, the skill of groups A and B with regard to the roughness of the processed surface is improved by the training system.
Based on the above, the skills of groups A and B have improved, whereas those of group $\mathrm{C}$ have not. The experiment has not enough number of subjects statistically, it should add more subjects in future work.

\section{CONCLUSION}

This study proposed a method for transferring explicit and tacit knowledge on lathe operation; a training system was developed with a simulator that uses relationship formulas between the speed of the tool feed and cutting sound/shape of chips proposed in the preceding study, on lathe operation based on an experiment with a trained worker. The effectiveness of the system was verified through the experiment.

Future work will involve examining the work conditions for lathe operation in detail, improving the training system, and implementing it in an actual factory.

\section{REFERENCES}

Antonietti, A., Imperio, E., Rasi, C., and Sacco, M. (2001), Virtual Reality and Hypermedia in Learning to Use a Turning Lathe, Journal of Computer Assisted Learning, 17, 142-155.

Doyo, D., Ohara, A., Shida, K., Matsumoto, T., and Otomo, K. (2009), A Method for Extracting Sensory Motor Skills and Designing a Training System, American Journal of Business Education, 2(8), 15-26.

Kawashimo, T., Doyo, D., Anse, M., and Matsumoto, T. 
(2012), Basic Study on Relationship between Speed of Tool Feed and Cutting Sound/Shape of Chips on Lathe Work, Journal of the Society of Plant Engineers Japan, 24(3), 129-135.

Liang, X., Kato, H., Higuchi, H., and Okawa, K. (2011), High Efficiency Skill Training of Boring Operation with Lathe by Means of Virtual Environment, Trans. of the Virtual Reality Society of Japan, 16(4), 533538.

Minister of Economy, Trade and Industry of Japan (2007), White Paper in 2007.

Nakajima, H., Kato, A., Sasahara, H., Yamamoto, H., Muraki, T., and Tsutsumi, M. (2008), Effect of Rotary Cutting Tool Posture on Machining Performance utilizing Multi-Tasking Lathe, Journal of $A d$ vanced Mechanical Design, Systems, and Manufacturing, 2(4), 532-539.

Nakamura, K. (1999), Illustration Science-Structure of Sound, Natsumesha.

Nakamura, Z. (2003), Objects-Changes Analysis, Nikkan
Kogyo Shimbun.

Shimizu, R., Shimosaka, H., and Ehara, N. (1997), Estimation for Proficiency of a Worker by using Cutting Sound, Transactions of the Japan Society of Mechanical Engineers, 1997(2), 159-160.

Suzuki, T., Shimosaka, H., and Ehara, N. (2006), Feed Rates Estimation by using Cutting Sound, Transactions of the Japan Society of Mechanical Engineers, 2006(41), 171-172.

Takechi, S. (2005), New Approach to Handing Down of Implicit Knowledge by Analytic Simulation, Journal of Japan Welding Society, 74(4), 213-216.

Takeshima, M., Yasuda, S., Shinoda, S., Matsumoto, T., Shinoda, M. (2014), Design of a Method to Analyze Skill from the Viewpoint of Transformation from Worker's Motion to Objects Change, Journal of Japan Industrial Management Association, 65(1), $1-8$.

Yokoyama, T. (2009), Point and Skill for Lathe Process, Nikkan Kogyo Shimbun. 